\title{
Effect of neoadjuvant chemoradiation on preoperative pulmonary physiology, postoperative respiratory complications and quality of life in patients with oesophageal cancer
}

\author{
J. A. Elliott \\ L. O'Byrne \\ Trinity College Dublin, Ireland \\ G. Foley \\ Trinity College Dublin, Ireland
}

Trinity College Dublin, Ireland, jelliott@tcd.ie

See next page for additional authors

Follow this and additional works at: https://arrow.tudublin.ie/scschbioart

Part of the Analytical, Diagnostic and Therapeutic Techniques and Equipment Commons, Oncology Commons, Palliative Care Commons, Radiation Medicine Commons, Respiratory Tract Diseases

Commons, and the Surgery Commons

\section{Recommended Citation}

J A Elliott, L O'Byrne, G Foley, C F Murphy, S L Doyle, S King, E M Guinan, N Ravi, J V Reynolds, Effect of neoadjuvant chemoradiation on preoperative pulmonary physiology, postoperative respiratory complications and quality of life in patients with oesophageal cancer, British Journal of Surgery, Volume 106, Issue 10, September 2019, Pages 1341-1351, DOI: 10.1002/bjs.11218

This Article is brought to you for free and open access by the School of Biological Sciences at ARROW@TU Dublin. It has been accepted for inclusion in Articles by an authorized administrator of ARROW@TU Dublin. For more information, please contact arrow.admin@tudublin.ie, aisling.coyne@tudublin.ie,gerard.connolly@tudublin.ie. Funder: Health Research Board, Ireland

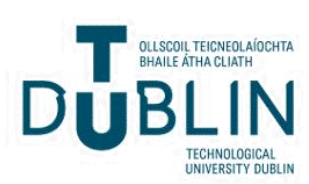




\section{Authors}

J. A. Elliott, L. O'Byrne, G. Foley, C. F. Murphy, Suzanne Doyle, S. King, E. M. Guinan, N. Ravi, and V. Reynolds 


\title{
Effect of neoadjuvant chemoradiation on preoperative pulmonary physiology, postoperative respiratory complications and quality of life in patients with oesophageal cancer
}

\author{
J. A. Elliott ${ }^{1}$, L. L’Byrne ${ }^{1}$, G. Foley ${ }^{2}$, C. F. Murphy ${ }^{1}$, S. L. Doyle ${ }^{1,3}$, S. King ${ }^{1}$, E. M. Guinan ${ }^{2}$, \\ N. Ravi ${ }^{1}$ and J. V. Reynolds ${ }^{1}$ \\ ${ }^{1}$ Department of Surgery, Trinity Centre for Health Sciences, Trinity College Dublin, and St James's Hospital, ${ }^{2}$ School of Medicine, Trinity College \\ Dublin, and ${ }^{3}$ School of Biological Sciences, Dublin Institute of Technology, Dublin, Ireland \\ Correspondence to: Dr J. A. Elliott, Department of Surgery, Trinity Centre and Institute of Molecular Medicine, St James's Hospital, Dublin 8, Ireland \\ (e-mail: jelliott@tcd.ie; @JElliottIRL, @emguinank, @SuzanneLDoyle, @CMASHL1F3, @Surgery_TCD, @stjamesdublin)
}

\begin{abstract}
Background: It remains controversial whether neoadjuvant chemoradiation (nCRT) for oesophageal cancer influences operative morbidity, in particular pulmonary, and quality of life. This study combined clinical outcome data with systematic evaluation of pulmonary physiology to determine the impact of nCRT on pulmonary physiology and clinical outcomes in locally advanced oesophageal cancer.

Methods: Consecutive patients treated between 2010 and 2016 were included. Three-dimensional conformal radiation was standard, with a lung dose-volume histogram of V20 less than 25 per cent, and total radiation between 40 and $41.4 \mathrm{~Gy}$. Forced expiratory volume in $1 \mathrm{~s}$ (FEV1), forced vital capacity (FVC) and diffusion capacity for carbon monoxide (DLCO) were assessed at baseline and 1 month after nCRT. Radiation-induced lung injury (grade 2 or greater), comprehensive complications index (CCI) and pulmonary complications were monitored prospectively. Health-related quality of life was assessed among disease-free patients in survivorship.

Results: Some 228 patients were studied. Comparing pulmonary physiology values before with those after nCRT, FEV1 decreased from mean(s.d.) $96 \cdot 8(17.7)$ to $91.5(20.4)$ per cent $(-3 \cdot 6(10 \cdot 6)$ per cent; $P<0.001)$, FVC from 104.9(15.6) to 98.1(19.8) per cent $(-3.2(11.9)$ per cent; $P=0.005)$ and DLCO from $97.6(20.7)$ to $82 \cdot 2(20.4)$ per cent $(-14.8(14.0)$ per cent; $P<0.001)$. Five patients $(2 \cdot 2$ per cent) developed radiation-induced lung injury precluding surgical resection. Smoking $(P=0.005)$ and increased age $(P<0.001)$ independently predicted percentage change in DLCO. Carboplatin and paclitaxel with 41.4 Gy resulted in a greater DLCO decline than cisplatin and 5 -fluorouracil with $40 \mathrm{~Gy}(P=0 \cdot 001)$. On multivariable analysis, post-treatment DLCO predicted CCI $(P=0.006)$, respiratory failure $(P=0.020)$ and reduced physical function in survivorship $(P=0 \cdot 047)$.

Conclusion: These data indicate that modern nCRT alters pulmonary physiology, in particular diffusion capacity, which is linked to short- and longer-term clinical consequences, highlighting a potentially modifiable index of risk.
\end{abstract}

Presented to the Annual Meeting of the European Surgical Association, Trieste, Italy, May 2018

Paper accepted 26 March 2019

Published online 8 July 2019 in Wiley Online Library (www.bjs.co.uk). DOI: 10.1002/bjs.11218

\section{Introduction}

Although recent trends indicate reduced postoperative mortality after oesophagectomy, major morbidity, in particular pulmonary, remains high, with considerable health and economic costs ${ }^{1}$. In a recent modern international collaborative series ${ }^{1}$ of 2704 patients from high-volume centres, with an approximately equal mix of open and minimally invasive approaches, major respiratory complications were evident in 28 per cent of patients, pneumonia in 15 per cent and respiratory failure in 7 per cent. In other series $^{1,2}$, respiratory failure was reported in up to 15 per cent of patients, and was the most common cause of death. The prediction of risk and prevention of respiratory morbidity are therefore of considerable importance, and in this 


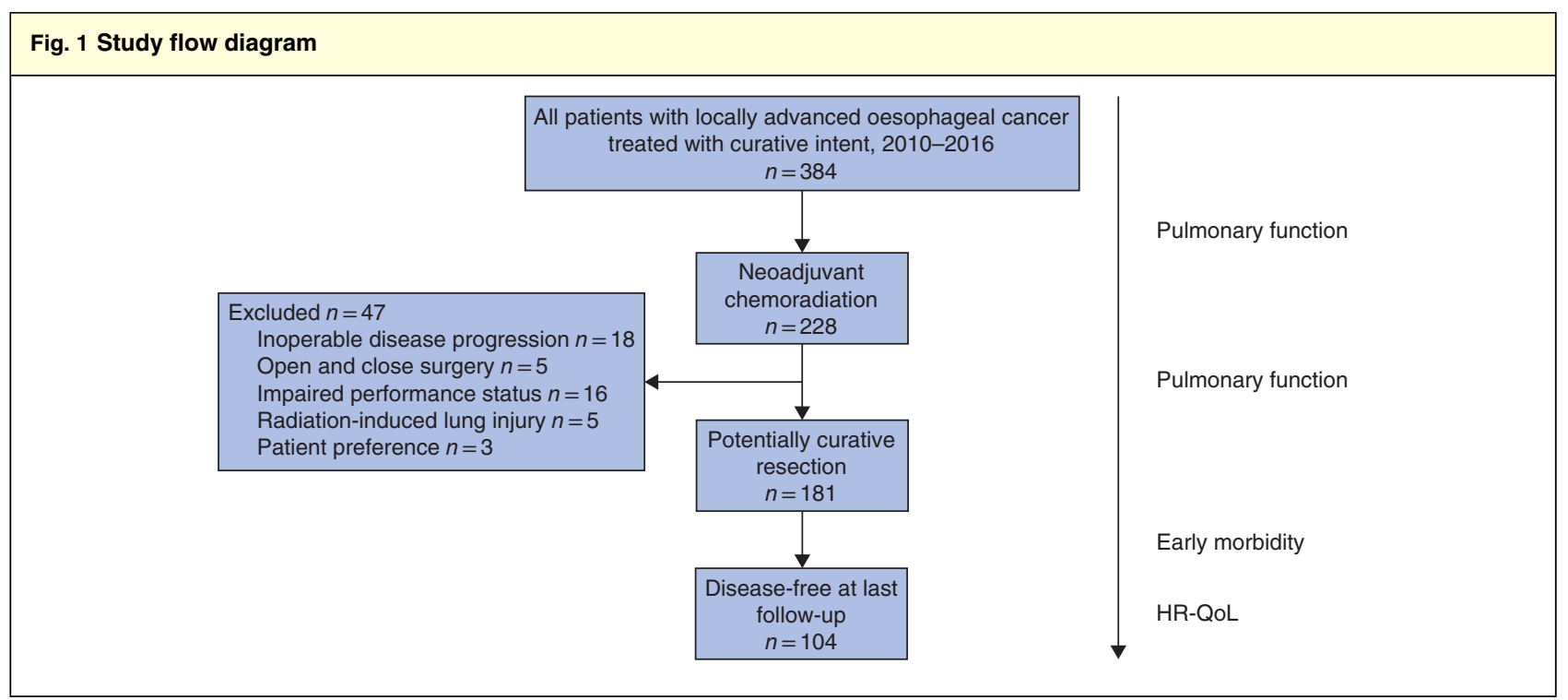

HR-QoL, health-related quality of life.

context baseline determination of lung physiology complements clinical assessment.

Neoadjuvant therapy is increasingly the standard of care for locally advanced oesophageal cancer, with the combination of chemotherapy and radiation therapy underpinned in the modern era by the CROSS trial (Chemoradiotherapy for Oesophageal Cancer Followed by Surgery Study) ${ }^{3}$, which combined 41.4 Gy, carboplatin and paclitaxel. The impact of radiation on lung physiology and its relevance to postoperative complications and survivorship are rarely studied. Modern radiation therapy is underpinned by three-dimensional (3D) conformal methods or intensity-modulated approaches, and dose-volume histograms (DVHs) are set to limit radiation delivery to non-target tissues such as lung; however, approximately 25 per cent of total lung tissue is irradiated up to $20 \mathrm{~Gy}$ in standard protocols. It remains unclear whether this has any clinical impact, in particular in relation to postoperative pulmonary complications. On the one hand, in the CROSS trial $^{3}$, where 46 per cent of patients experienced pulmonary complications in the multimodal cohort, there was no difference compared with surgery alone, with a 4 per cent operative mortality rate in both cohorts. Moreover, a meta-analysis ${ }^{4}$ of RCTs including 431 patients showed no added risk of respiratory complications or operative mortality with a variety of multimodal protocols. Conversely, several studies have suggested caution in this interpretation, as chemoradiation was associated with a significant fourfold increased operative mortality rate in the FFCD (Fédération Francophone de Cancérologie Digestive) 9901 $\mathrm{RCT}^{5}$, a threefold but non-significant increase in mortality compared with chemotherapy in the POET (PreOperative therapy in Esophagogastric adenocarcinoma) trial ${ }^{6}$, and a non-significant doubling of mortality in the NeoRes (Neoadjuvant Chemotherapy Versus Radiochemotherapy for Cancer of the Esophagus or Cardia) trial ${ }^{7}$, with a significant increase in major pulmonary complications. It is also inarguable that, until recently, the definition, prospective documentation and reporting of operative morbidity, including pneumonia and pulmonary complications, in published RCTs were relatively weak and inconsistent ${ }^{8}$. Accordingly, the question of whether neoadjuvant chemoradiation (nCRT) has a clinical or a more nuanced impact on pulmonary function remains of great relevance, and demands rigorous assessment. In this study, lung function was measured systematically before and after nCRT, and the incidence of clinically evident radiation-induced lung injury, subclinical changes in physiology that may be linked to postoperative complications, and quality of life in survivorship were evaluated.

\section{Methods}

The Oesophageal and Gastric Centre at St James's Hospital, Dublin, is a high-volume national centre, and a detailed clinicopathological database is maintained prospectively for all patients with oesophageal cancer. Records for consecutive patients with locally advanced oesophageal cancer treated with nCRT with curative intent over 7 years between 2010 and 2016 were assessed retrospectively for inclusion. Patients undergoing emergency or palliative surgery, or salvage oesophagectomy, were excluded. 


\begin{tabular}{|c|c|}
\hline & No. of patients ${ }^{*}(n=181)$ \\
\hline \multicolumn{2}{|l|}{ Clinical characteristics } \\
\hline Age (years) $\dagger$ & $60 \cdot 9(9 \cdot 4)$ \\
\hline Sex ratio $(F: M)$ & $46: 135$ \\
\hline Bodyweight $(\mathrm{kg}) \dagger$ & $77 \cdot 7(16 \cdot 4)$ \\
\hline BMI $\left(\mathrm{kg} / \mathrm{m}^{2}\right) \dagger$ & $27 \cdot 0(4 \cdot 8)$ \\
\hline Visceral obesity & 55 of $127(43 \cdot 3)$ \\
\hline Sarcopenia & 29 of $127(22 \cdot 8)$ \\
\hline \multicolumn{2}{|l|}{ Smoker } \\
\hline Ever smoker & $125(69 \cdot 1)$ \\
\hline Current smoker & $56(31.0)$ \\
\hline Pack-years $\dagger$ & $21 \cdot 7(28 \cdot 5)$ \\
\hline Diabetes & $13(7 \cdot 2)$ \\
\hline Ischaemic heart disease & $19(10 \cdot 5)$ \\
\hline Hypertension & $70(38 \cdot 7)$ \\
\hline Respiratory comorbidity & $34(18 \cdot 8)$ \\
\hline COPD & $14(7 \cdot 7)$ \\
\hline Asthma & $10(5 \cdot 5)$ \\
\hline \multicolumn{2}{|l|}{ ASA fitness grade } \\
\hline 1 & $90(49 \cdot 7)$ \\
\hline II & $77(42 \cdot 5)$ \\
\hline III & $14(7 \cdot 7)$ \\
\hline \multicolumn{2}{|l|}{ Pathological characteristics } \\
\hline \multicolumn{2}{|l|}{ Histological type } \\
\hline Adenocarcinoma & $133(73.5)$ \\
\hline Squamous cell carcinoma & $48(26 \cdot 5)$ \\
\hline \multicolumn{2}{|l|}{ Tumour location } \\
\hline Middle & $12(6 \cdot 6)$ \\
\hline Lower & $37(20.4)$ \\
\hline Junctional & $132(72.9)$ \\
\hline \multicolumn{2}{|l|}{ Clinical category } \\
\hline cT1 & $2(1 \cdot 1)$ \\
\hline cT2 & $26(14.4)$ \\
\hline cT3 & $149(82 \cdot 3)$ \\
\hline cT4 & $4(2 \cdot 2)$ \\
\hline cNO & $79(43.6)$ \\
\hline $\mathrm{cN} 1$ & $78(43 \cdot 1)$ \\
\hline cN2 & $21(11 \cdot 6)$ \\
\hline cN3 & $3(1 \cdot 7)$ \\
\hline \multicolumn{2}{|l|}{ Pathological category } \\
\hline урто & $39(21.5)$ \\
\hline ypT1 & $31(17 \cdot 1)$ \\
\hline урт2 & $27(14.9)$ \\
\hline урТ3 & $78(43 \cdot 1)$ \\
\hline урT4 & $6(3 \cdot 3)$ \\
\hline ypNO & $109(60 \cdot 2)$ \\
\hline ypN1 & $43(23 \cdot 8)$ \\
\hline ypN2 & $22(12 \cdot 2)$ \\
\hline ypN3 & $7(3.9)$ \\
\hline
\end{tabular}

Pulmonary function testing was undertaken routinely for all patients being considered for surgery. All eligible

\begin{tabular}{|cc|}
\hline Table 1 Continued & \\
\hline & No. of patients* $(\boldsymbol{n}=\mathbf{1 8 1})$ \\
Tumour regression grade & \\
TRG 1 & $40(22 \cdot 1)$ \\
TRG 2 & $46(25 \cdot 4)$ \\
TRG 3 & $52(28 \cdot 7)$ \\
TRG 4 & $30(16 \cdot 6)$ \\
TRG 5 & $7(3.9)$ \\
Not applicable & $6(3.3)$ \\
PCR & $33(18 \cdot 2)$ \\
R0 resection & $171(94.5)$ \\
\hline
\end{tabular}

*With percentages in parentheses unless indicated otherwise; †values are mean(s.d.). COPD, chronic obstructive pulmonary disease; pCR, pathological complete response.

patients for whom pulmonary function data were available at a minimum of one preoperative time point were included in the analysis of operative and/or oncological outcomes. Health-related quality of life (HR-QoL) among disease-free patients was assessed using validated questionnaires (European Organisation for Research and Treatment of Cancer (EORTC) QLQ-C30, QLQ-OG25 and QLQ-OES18) $)^{9,10}$.

The study was approved by the institutional review board and registered at ClinicalTrials.gov (NCT03462524).

\section{Neoadjuvant therapy and surgery}

During the trial, patients with locally advanced oesophageal cancer received nCRT, either cisplatin and 5 -fluorouracil (5-FU) with $40 \mathrm{~Gy}$ in 15 fractions or carboplatin and paclitaxel with $41.4 \mathrm{~Gy}$ in 23 fractions) $)^{3,11}$, or perioperative chemotherapy (etoposide, cisplatin, fluorouracil or capecitabine $)^{12}$. A lung DVH of V20 (total lung volume receiving less than 20 Gy of radiation) below 25 per cent was set, with total radiation between 40 and 41.4 Gy, and delivery by 3D conformal methods. Patients underwent resection approximately 6 weeks after completion of nCRT. The operative approach entailed open oesophagectomy with a gastric conduit and thoracic or cervical anastomosis, or extended total gastrectomy with mediastinal Roux-en-Y reconstruction ${ }^{13,14}$; transhiatal resection was used selectively in higher-risk patients ${ }^{13}$.

Single-lung ventilation was achieved using a double-lumen endotracheal tube. A multidisciplinary enhanced recovery protocol was used, with intraoperative fluid restricted to $500 \mathrm{ml} / \mathrm{h}$, thoracic epidural, immediate extubation and mobilization on day 1 as standard in this interval, with all patients post oesophagectomy monitored in a critical care setting for at least the first 


\begin{tabular}{|c|c|}
\hline & No. of patients ${ }^{*}(n=181)$ \\
\hline \multicolumn{2}{|l|}{ Chemoradiation regimen } \\
\hline Cisplatin, 5-fluorouracil, 40 Gy/15 fractions & $79(43 \cdot 6)$ \\
\hline Carboplatin, paclitaxel, $41.4 \mathrm{~Gy} / 23$ fractions & $101(55 \cdot 8)$ \\
\hline Missing & $1(0 \cdot 6)$ \\
\hline \multicolumn{2}{|l|}{ Operation type } \\
\hline Extended total gastrectomy & $6(3 \cdot 3)$ \\
\hline 2-stage oesophagectomy & $109(60 \cdot 2)$ \\
\hline 3-stage oesophagectomy & $50(27 \cdot 6)$ \\
\hline Transhiatal oesophagectomy & $16(8 \cdot 8)$ \\
\hline Comprehensive complications index score $\dagger$ & $20 \cdot 2(19 \cdot 2)$ \\
\hline \multicolumn{2}{|l|}{ Clavien-Dindo grade } \\
\hline No complication & $51(28 \cdot 2)$ \\
\hline Grade I & $24(13 \cdot 3)$ \\
\hline Grade II & $51(28 \cdot 2)$ \\
\hline Grade IIla & $27(14.9)$ \\
\hline Grade IIIb & $5(2 \cdot 8)$ \\
\hline Grade IVa & $9(5 \cdot 0)$ \\
\hline Grade IVb & $12(6 \cdot 6)$ \\
\hline$\geq I I I b$ & $28(15.5)$ \\
\hline Anastomotic leak & $10(5 \cdot 5)$ \\
\hline Pulmonary complication & $80(44 \cdot 2)$ \\
\hline Major pulmonary complication & $26(14.4)$ \\
\hline Pneumonia & $56(30.9)$ \\
\hline Prolonged intubation & $24(13 \cdot 3)$ \\
\hline Atrial fibrillation & $36(19.9)$ \\
\hline Major cardiac morbidity & $3(1 \cdot 7)$ \\
\hline Critical care LOS (days) $\ddagger$ & $4(0-85)$ \\
\hline Inpatient LOS (days): & $16(6-201)$ \\
\hline In-hospital death & $2(1 \cdot 1)$ \\
\hline
\end{tabular}

*With percentages in parentheses unless indicated otherwise; values are $\dagger$ mean(s.d.) and $\ddagger$ median (range). Major postoperative pulmonary complication defined as grade IIIb or greater. LOS, length of stay.

$48 \mathrm{~h}$ after surgery. All patients were seen by respiratory physiotherapists on the day after operation and underwent personalized intensive respiratory physiotherapy until discharge. A 10-Fr needle catheter jejunostomy was routinely placed at surgery, and feeding commenced on the first postoperative day ${ }^{15}$. All patients underwent nutritional and physiotherapy assessment at a multidisciplinary clinic at diagnosis, before surgery and at serial postoperative time points, as described previously ${ }^{16,17}$.

Postoperative complications were coded using the Clavien-Dindo classification ${ }^{18}$ and comprehensive complications index $(\mathrm{CCI})^{19}$. Postoperative pulmonary complications were defined according to the criteria of the Esophageal Complications Consensus Group ${ }^{20}$, and pneumonia was diagnosed clinically in accordance with guidelines of the Centers for Disease Control and
Prevention $^{21}$. Prolonged intubation was defined as respiratory failure of any aetiology requiring reintubation or mechanical ventilation more than $24 \mathrm{~h}$ after operation.

\section{Pulmonary function testing}

Pulmonary physiology, including diffusion capacity for carbon monoxide (DLCO), forced expiratory volume in $1 \mathrm{~s}$ (FEV1) and forced vital capacity (FVC), was assessed in the pulmonary laboratory at baseline and 1 month after completion of neoadjuvant therapy using the Vmax ${ }^{\circledR}$ Encore PFT system (Vyaire Medical, Mettawa, Illinois, USA), in accordance with European Respiratory Society (ERS) and American Thoracic Society technical standards ${ }^{22}$. DLCO values are expressed uncorrected, in SI units (mmol per min per $\mathrm{kPa}$ ), in accordance with ERS guidelines ${ }^{22}$. Reference values normalized for age, sex, height and ethnicity were generated using Global Lung Function Initiative equations; pulmonary function measures are expressed as the percentage of predicted values ${ }^{23,24}$. Radiation-induced lung injury was defined according to EORTC common toxicity criteria, and the incidence of lung injury of grade 2 or above was monitored.

\section{Statistical analysis}

Continuous data are reported as mean(s.d.) unless specified otherwise. Univariable comparisons were performed using linear regression, Student's $t$ test or the Mann-Whitney $U$ test for continuous variables, and the $\chi^{2}$ or Fisher's exact test for categorical variables. For multivariable analyses, clinically relevant variables were included in linear, logistic or Cox proportional hazards regression models using a forward stepwise selection procedure. The predictive accuracy of baseline pulmonary function with respect to subsequent radiation-induced lung injury was assessed using receiver operating characteristic (ROC) curve analysis. $P<0.050$ was considered statistically significant. Data were analysed using GraphPad Prism ${ }^{\circledR}$ version 6.0 for Windows ${ }^{\circledR}$ (GraphPad Software, San Diego, California, USA) and SPSS ${ }^{\circledR}$ version 23.0 (IBM, Armonk, New York, USA).

\section{Results}

A total of 228 patients received nCRT and these represent the study cohort (Fig. 1). One hundred and thirty-three patients (58.3 per cent) received carboplatin and paclitaxel with $41.4 \mathrm{~Gy}$, whereas 93 (40.8 per cent) received cisplatin and 5-FU with $40 \mathrm{~Gy}$; the regimen was not available for two patients who had nCRT at another hospital. Some 181 patients underwent resection with curative 


\section{Fig. 2 Changes in pulmonary function after neoadjuvant chemoradiation}

a FEV1

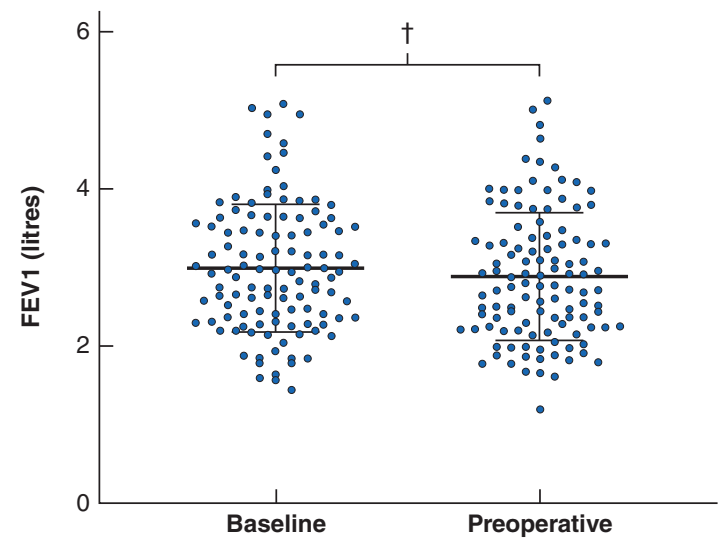

C FEV1/FVC

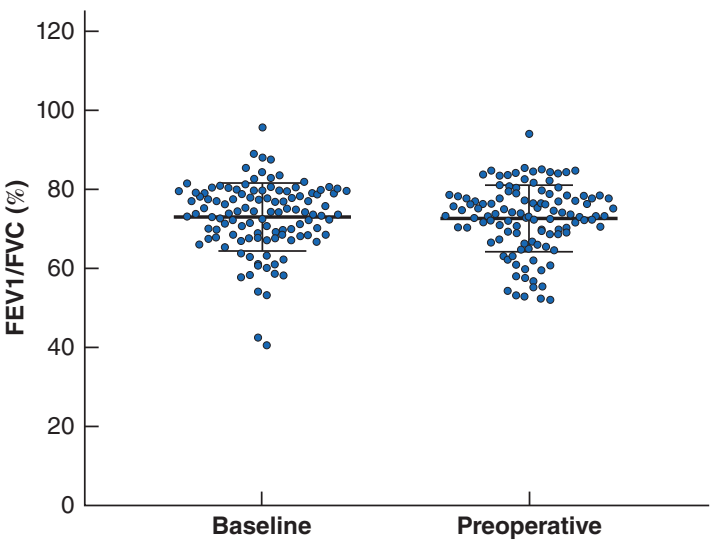

b FVC

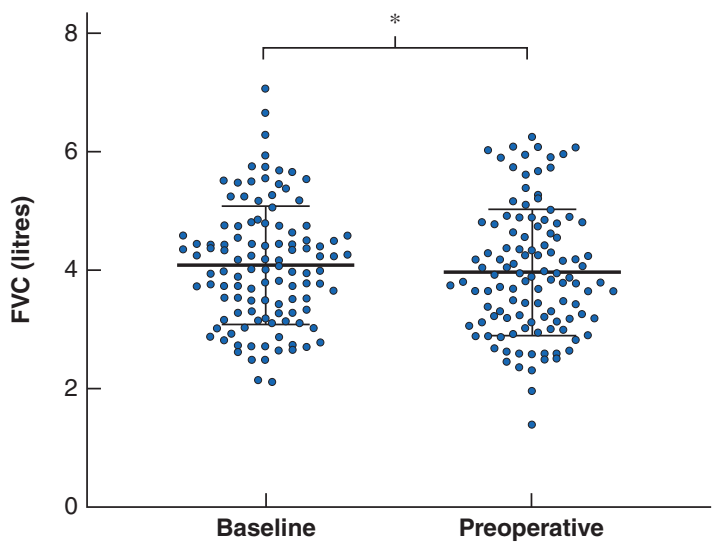

d DLCO

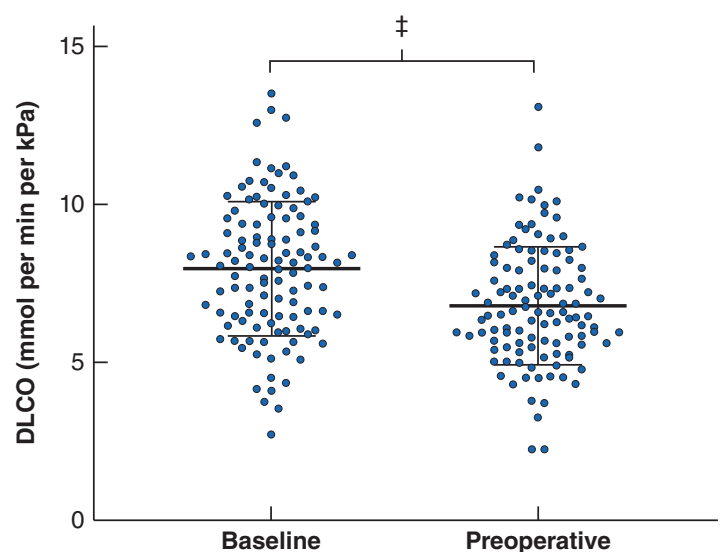

\section{Change in pulmonary function following neoadjuvant therapy}

A statistically significant decline in FEV1 from 96.8(17.7) to $91.5(20.4)$ per cent $(-3 \cdot 6(10 \cdot 6)$ per cent; $P<0 \cdot 001)$, FVC from 104.9(15.6) to $98 \cdot 1(19 \cdot 8)$ per cent $(-3 \cdot 2(11.9)$ per cent; $P=0.005)$ and DLCO from $97 \cdot 6(20.7)$ to $82 \cdot 2(20.4)$ per cent $(-14.8(14.0)$ per cent; $P<0.001)$ was observed after nCRT (Fig. 2 and Table 3). The post-treatment change in percentage predicted DLCO was unrelated to percentage changes in haemoglobin
$\left(R^{2}=0.03, P=0.344\right)$. No change in the $\mathrm{FEV} 1 / \mathrm{FVC}$ ratio was noted $(P=0.552)$.

Reduced post-treatment DLCO was independently associated with smoking $(P=0.005)$ and increased age $(P<0.001)$, whereas smoking was independently associated with a greater absolute and relative decline in DLCO (Table S1, supporting information). Patients treated with carboplatin and paclitaxel with $41.4 \mathrm{~Gy}$ had greater baseline DLCO values than those receiving cisplatin and 5-FU with 40 Gy $(101 \cdot 3(18 \cdot 3)$ versus $88.3(23 \cdot 6)$ per cent; $P=0.003)$. However, the decline in DLCO was greater in this group $(-16 \cdot 2(12 \cdot 2)$ versus $-5 \cdot 1(16 \cdot 8)$ per cent; $P=0.001)$; this persisted after accounting for baseline DLCO and smoking on multivariable analysis ( $\beta$ (s.e.) 95 per cent c.i. $-9.67(2.89)$ to $15.42(3.92) ; P=0.001)$. Post- 


\begin{tabular}{|c|c|}
\hline \multicolumn{2}{|c|}{$\begin{array}{l}\text { Table } 3 \text { Pulmonary function measured at baseline and after } \\
\text { neoadjuvant chemoradiation (before surgery) in patients who } \\
\text { had surgery }\end{array}$} \\
\hline \multicolumn{2}{|l|}{ Baseline } \\
\hline FEV1 (litres) & $2.94(0.82)$ \\
\hline FEV1 (\% predicted) & $96 \cdot 8(17 \cdot 7)$ \\
\hline FVC (litres) & $4.09(0.98)$ \\
\hline FVC (\% predicted) & $104 \cdot 9(15 \cdot 6)$ \\
\hline FEV1/FVC (\%) & $71 \cdot 7(9 \cdot 6)$ \\
\hline DLCO (mmol per min per $\mathrm{kPa})$ & $7 \cdot 83(2 \cdot 20)$ \\
\hline DLCO (\% predicted) & $97 \cdot 6(20 \cdot 7)$ \\
\hline \multicolumn{2}{|l|}{ Preoperative } \\
\hline FEV1 (litres) & $2 \cdot 81(0 \cdot 81)$ \\
\hline FEV1 (\% predicted) & $91 \cdot 5(20 \cdot 4)$ \\
\hline FVC (litres) & $3.87(1.03)$ \\
\hline FVC (\% predicted) & $98 \cdot 1(19 \cdot 8)$ \\
\hline FEV1/FVC (\%) & $72 \cdot 6(9 \cdot 3)$ \\
\hline DLCO (mmol per min per $\mathrm{kPa})$ & $6 \cdot 62(1 \cdot 81)$ \\
\hline DLCO (\% predicted) & $82 \cdot 2(20 \cdot 4)$ \\
\hline \multicolumn{2}{|l|}{ Change in pulmonary function } \\
\hline$\Delta \mathrm{FEV} 1$ & $-0 \cdot 10(0 \cdot 34)$ \\
\hline$\Delta \mathrm{FVC}$ & $-0.11(0.50)$ \\
\hline$\triangle \mathrm{DLCO}$ & $-1 \cdot 20(1 \cdot 14)$ \\
\hline$\% \Delta \mathrm{FEV} 1$ & $-2 \cdot 8(13 \cdot 2)$ \\
\hline$\% \Delta \mathrm{FVC}$ & $-2 \cdot 8(11 \cdot 5)$ \\
\hline$\% \Delta \mathrm{DLCO}$ & $-14 \cdot 0(13 \cdot 8)$ \\
\hline
\end{tabular}

Values are mean(s.d.). FEV1, forced expiratory volume in $1 \mathrm{~s}$; FVC, forced vital capacity; DFCO, diffusion capacity for carbon monoxide. $\Delta$, change in.

treatment DLCO values were similar in the two treatment groups (83.5(20.7) versus 79.9(19.9) per cent; $P=0.273)$.

After nCRT, five patients (2.2 per cent) developed radiation-induced lung injury precluding surgical resection. Patients with lung injury exhibited a greater relative change in FEV1 $(-18 \cdot 6(14 \cdot 1)$ versus $-2 \cdot 1(12 \cdot 9)$ per cent; $P=0.002)$, FVC $(-21.4(16.7)$ versus $-2.0(10 \cdot 8)$ per cent; $P=0.002)$ and DLCO $(-29.9(10.9)$ versus $-13.4(13.7)$ per cent; $P=0.019)$ during treatment, and significantly reduced post-treatment DLCO $(52.5(12 \cdot 8)$ versus $82.9(20.0)$ per cent; $P=0.003)$. Radiation-induced lung injury was associated with lower baseline DLCO values $(74.1(8.8)$ versus $98 \cdot 2(20 \cdot 6)$ per cent; $P=0.021)$ and a history of respiratory co-morbidity ( 3 of 5 ( 60 per cent) versus 46 of 223 (20.6 per cent); $P=0.034)$. Neither baseline FEV1 and FVC, nor neoadjuvant chemoradiation regimen, predicted subsequent radiation-induced lung injury.

On ROC analysis, baseline DLCO demonstrated 85 (s.e. 4) per cent accuracy $(P=0.017)$ for the prediction of subsequent lung injury precluding surgery (Fig. 3). A threshold baseline DLCO of less than 81.5 per cent

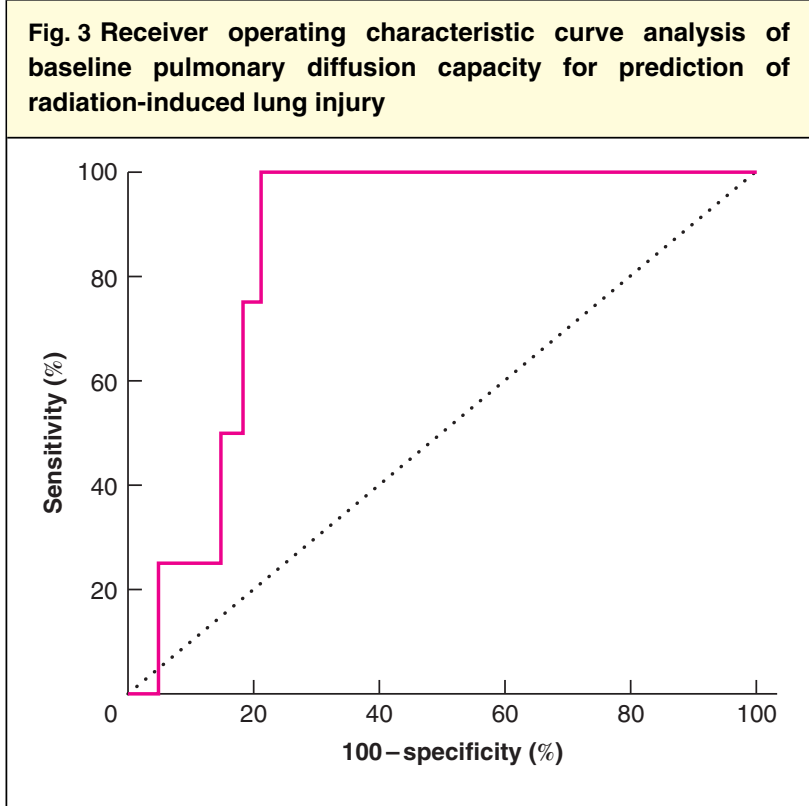

On receiver operating characteristic (ROC) curve analysis, baseline diffusion capacity for carbon monoxide predicted subsequent radiation-induced lung injury precluding operation with 85 (s.e.4) per cent accuracy $(P=0 \cdot 017)$.

predicted radiation-induced lung injury with 100 per cent sensitivity and 79 per cent specificity.

\section{Neoadjuvant therapy, pulmonary function and operative morbidity}

Among the 181 patients who underwent resection, pulmonary complications, major pulmonary complications and prolonged intubation for respiratory failure occurred in 80 (44.2 per cent), 26 (14.4 per cent) and 24 (13.3 per cent) patients, with an in-hospital mortality rate of 1.1 per cent (2 patients died) (Table 2). Reduced FVC independently predicted the risk of pneumonia (odds ratio (OR) $0.97,95$ per cent c.i. 0.95 to 0.99 ) (Table 4 ) and postoperative pulmonary complications (OR $0.96,0.94$ to 0.99 ).

Patients who required prolonged intubation for respiratory failure had significantly lower preoperative DLCO (75.4(17.8) versus $85.4(19.6)$ per cent; $P=0.030)$, but not FEV1 (95.6(25.4) versus $97.6(16.7)$ per cent; $P=0.666)$ or FVC (100.0(14.8) versus $105 \cdot 6(15 \cdot 4)$ per cent; $P=0 \cdot 170)$. On multivariable analysis, lower post-treatment DLCO (OR 0.97, 0.94 to 1.00 ) and increased FEV1/FVC ratio (OR 1.09 1.02 to 1.16), indicative of a restrictive pattern of lung disease, independently predicted the risk of prolonged intubation (Table 4). A threshold DLCO of less than 65.0 per cent demonstrated 90 per cent specificity for the prediction of prolonged intubation. 


\begin{tabular}{|c|c|c|c|c|c|c|c|c|}
\hline & \multicolumn{4}{|c|}{ Pneumonia } & \multicolumn{4}{|c|}{ Prolonged intubation } \\
\hline & \multicolumn{2}{|c|}{ Univariable analysis } & \multicolumn{2}{|c|}{ Multivariable analysis } & \multicolumn{2}{|c|}{ Univariable analysis } & \multicolumn{2}{|c|}{ Multivariable analysis } \\
\hline & Odds ratio & $\boldsymbol{P}$ & Odds ratio & $\boldsymbol{P}$ & Odds ratio & $\boldsymbol{P}$ & Odds ratio & $\boldsymbol{P}$ \\
\hline \multicolumn{9}{|l|}{ Clinical characteristics } \\
\hline Age (years) ${ }^{\star}$ & $1.04(1.00,1.08)$ & 0.028 & $1.06(1.01,1.11)$ & 0.011 & $1.07(1.01,1.13)$ & 0.021 & $1.07(1.01,1.14)$ & 0.038 \\
\hline Sex (M versus $F)$ & $1.29(0.62,2 \cdot 69)$ & 0.489 & & 0.208 & $1.44(0.51,4.10)$ & 0.493 & & 0.290 \\
\hline Weight $(\mathrm{kg})^{\star}$ & $1.00(0.98,1.02)$ & 0.788 & & 0.888 & $1.00(0.98,1.03)$ & 0.747 & & 0.811 \\
\hline ASA grade $\dagger$ & & 0.824 & & 0.856 & & 0.381 & & 0.824 \\
\hline Smoking $\dagger$ & & 0.896 & & 0.783 & & 0.600 & & 0.914 \\
\hline Diabetes & $0.67(0.18,2.53)$ & 0.552 & & 0.234 & $0.54(0.07,4.32)$ & 0.558 & & 0.188 \\
\hline Ischaemic heart disease & $1.38(0.51,3.72)$ & 0.523 & & 0.584 & $1.93(0.58,6.41)$ & 0.281 & & 0.814 \\
\hline Respiratory co-morbidity & $1.12(0.50,2.48)$ & 0.788 & & 0.713 & $0.87(0.28,2.72)$ & 0.806 & & 0.856 \\
\hline Asthma & $0.98(0.24,3.93)$ & 0.975 & & 0.745 & $0.73(0.09,6.03)$ & 0.770 & & 0.808 \\
\hline COPD & $1.30(0.41,4.06)$ & 0.656 & & 0.689 & $1.12(0.24,5.35)$ & 0.886 & & 0.853 \\
\hline Histological type & $1.55(0 \cdot 77,3 \cdot 10)$ & $0 \cdot 218$ & & 0.287 & $1.20(0.46,3.09)$ & 0.713 & & 0.825 \\
\hline $\begin{array}{l}\text { Chemoradiation regimen (CROSS } \\
\text { regimen versus cisplatin/5-FU/40 Gy) }\end{array}$ & $1 \cdot 17(0 \cdot 62,2 \cdot 21)$ & 0.632 & & 0.738 & $1.66(0.67,4.09)$ & 0.275 & & 0.238 \\
\hline $\begin{array}{l}\text { Operative approach (transthoracic } \\
\text { versus transhiatal) }\end{array}$ & $0.81(0.31,2 \cdot 16)$ & 0.677 & & 0.925 & $0.85(0.23,3.15)$ & 0.808 & & 0.627 \\
\hline \multicolumn{9}{|l|}{ Preoperative pulmonary function ${ }^{\star}$} \\
\hline FEV1 (litres) & $0.64(0.41,1.01)$ & 0.057 & & 0.273 & $0.85(0.47,1.56)$ & 0.601 & & 0.633 \\
\hline FEV1 (\% predicted) & $0.98(0.97,1.00)$ & 0.069 & & 0.087 & $0.99(0.97,1.02)$ & 0.664 & & 0.845 \\
\hline FVC (per litre) & $0.63(0.43,0.92)$ & 0.016 & & 0.898 & $0.72(0.43,1.19)$ & $0 \cdot 199$ & & 0.726 \\
\hline FVC (\% predicted) & $0.97(0.95,0.99)$ & 0.005 & $0.97(0.95,0.99)$ & 0.004 & $0.98(0.96,1.00)$ & 0.094 & & 0.938 \\
\hline FEV1/FVC (\%) & $1.02(0.98,1.06)$ & 0.297 & & 0.054 & $1.05(0.99,1.11)$ & $0 \cdot 137$ & $1.09(1.02,1.16)$ & 0.011 \\
\hline DLCO (mmol per min per $\mathrm{kPa})$ & $0.84(0.69,1.04)$ & 0.111 & & 0.525 & $0.74(0.54,1.00)$ & 0.051 & & 0.916 \\
\hline DLCO (\% predicted) & $0.99(0.97,1.00)$ & $0 \cdot 113$ & & 0.425 & $0.98(0.95,1.00)$ & 0.038 & $0.97(0.94,1.00)$ & 0.020 \\
\hline
\end{tabular}

Values in parentheses are 95 per cent confidence intervals. COPD, chronic obstructive pulmonary disease; 5-FU, 5-fluorouracil; FEV1, forced expiratory volume in $1 \mathrm{~s}$; FVC, forced vital capacity; DFCO, diffusion capacity for carbon monoxide. *Odds ratios for continuous variables are shown per unit increase. $\dagger$ Analysed as a categorical variable; individual category $P$ values and odds ratios not significant.

Reduced post-treatment DLCO was associated with increased CCI on univariable analysis $(P=0.010)$, whereas lower post-treatment DLCO $(P=0.006)$ and increased FEV1/FVC ratio $(P=0.009)$ independently predicted CCI on multivariable analysis (Table $S 2$, supporting information).

\section{Pulmonary function and health-related quality of life}

Among those who were disease-free 1 year or more after surgery (104 patients, with HR-QoL data available for 40), reduced post-nCRT DLCO was associated with poorer physical function $(P=0.047)$ and subjective trouble taking a long outdoor walk $(P=0 \cdot 011)$. The neoadjuvant regimen did not influence physical function or HR-QoL in survivorship. Similarly, no baseline or post-treatment pulmonary function parameter had a significant impact on overall HR-QoL. On multivariable analysis, background respiratory co-morbidity $(P=0.011)$ and lower post-treatment DLCO $(P=0.038)$ independently predicted poorer physical function scores.

\section{Discussion}

This study has highlighted the fact that pulmonary physiology is altered negatively by modern nCRT protocols, and the impact, although nuanced and subclinical, can have a direct influence on risks of postoperative pulmonary complications and recovery of quality of life. Although FEV1 and FVC were significantly reduced by nCRT, the loss of diffusion capacity, measured by DLCO, was most pronounced and associated with clinical outcomes. The overall mean decrease in DLCO was 14.8 per cent compared with less than 4 per cent each for FEV1 and FVC, the latter functional lung volume data being consistent with those of the NeoRes trial ${ }^{25}$. In NeoRes, however, DLCO was not measured and, despite detailed 
cardiopulmonary evaluation, the increased burden of major pulmonary morbidity among patients treated with nCRT remained unexplained.

On the other hand, in a study of 20 patients receiving $50 \cdot 4 \mathrm{~Gy}$, oxaliplatin and 5-FU, Gergel and colleagues ${ }^{26}$ reported a 16.9 per cent reduction in DLCO, with a decrease of 2.5 per cent in total lung capacity. Similarly, in a study from the Cleveland Clinic ${ }^{27}$, including 155 patients treated with a combination regimen including cisplatin and 5-FU, 108 of whom received 45 Gy and 47 received 30 Gy, decreases in DLCO of 21.7 and 8.6 per cent respectively were observed ${ }^{27}$. This dose-response effect is consistent with the results of Riedel et al..$^{28}$, who reported no significant change in pulmonary function in 77 patients with locally advanced oesophageal cancer, with grade 1 radiation-induced lung injury in just one patient (1 per cent) after treatment with 5 -FU and $30 \mathrm{~Gy}$.

In the present study, although radiation doses were similar and the chemotherapy regimens varied, a greater decline in DLCO was observed following administration of the CROSS regimen (carboplatin, paclitaxel and $41.4 \mathrm{~Gy}$ ) compared with cisplatin, 5-FU and $40 \mathrm{~Gy}$. Although baseline differences in pulmonary function, and the non-contemporaneous nature of the cohorts, preclude definitive conclusions being drawn from these data, administration of carboplatin and paclitaxel with neoadjuvant radiation has been reported to increase synergistically the risk of radiation-induced lung injury, with a $3 \cdot 3$-fold increased risk of at least grade 2 lung injury among patients with non-small cell lung carcinoma, and increased pneumonitis in those with oesophageal cancer ${ }^{29,30}$. Furthermore, in a contemporaneous cohort of 156 patients undergoing neoadjuvant chemotherapy at the authors' centre, although reductions in DLCO were observed $(P<0.001)$, the relative reduction in DLCO was significantly greater after chemoradiation $(-14 \cdot 8(14 \cdot 0)$ per cent for nCRT in the present cohort versus -7.3(14.9) per cent for neoadjuvant chemotherapy in the contemporaneous cohort; $P=0.003$ ), and on multivariable analysis chemoradiation independently predicted the absolute $(P=0 \cdot 017)$ and relative $(P=0.018)$ decline in DLCO during neoadjuvant treatment (data not shown). Importantly, in the present study, reduced baseline DLCO was associated with an increased risk of lung injury precluding surgery, with a threshold of less than 81.5 per cent exhibiting 79 per cent specificity for prediction of such injury.

Although clinically evident lung injury is rare, observed in just five patients here $(2 \cdot 2$ per cent), this study has identified important associations between reduced diffusion capacity and clinical consequences, in particular respiratory failure, prolonged intubation, increased
CCI and major pulmonary morbidity. Specifically, a post-treatment DLCO of less than 65.0 per cent predicted postoperative respiratory failure and prolonged intubation with 90 per cent specificity. The mechanisms linking changes in pulmonary physiology to postoperative complications require further investigation. Whether radiation-induced lung injury occurs as a consequence of direct radiation injury, perhaps in synergy with taxaneinduced pneumonitis, or a 'first hit' sensitization or priming of alveolar and immune cells to an exaggerated immune and inflammatory response to a 'second hit' such as single-lung ventilation, bacteraemia or pneumonia, is uncertain ${ }^{31}$. Fibrosis is thought to occur owing to activation of latent transforming growth factor (TGF) $\beta$, which increases the generation of reactive oxygen species via reduced nicotinamide adenine dinucleotide phosphate oxidases and resulting activation of SMAD, stimulating myofibroblast proliferation via epithelial-to-mesenchymal transition, and promoting extracellular matrix deposition ${ }^{31}$. These changes perpetuate tissue hypoxia and manifest as impaired diffusion, with overt fibrosis and hypoxemia its most severe clinical expression. Experimentally, increased circulating levels of TGF- $\beta 1$, as well as interleukin (IL) $1 \alpha$, IL-6 and monocyte chemoattractant protein 1 , have been demonstrated during the development of radiation-induced lung injury, suggesting the possibility of biomarker development to facilitate treatment modification when features of lung injury are detected ${ }^{32}$.

In the present cohort, no difference in postoperative pulmonary morbidity was observed among patients undergoing transhiatal compared with transthoracic resection, which is probably a reflection of selective use of this operative strategy for high-risk patients; the baseline pulmonary co-morbidity rate was 45.0 per cent for patients having a transhiatal procedure compared with 15.5 per cent for those undergoing a transthoracic procedure $(P=0 \cdot 004)$. A transhiatal approach has been suggested for patients with significant pulmonary co-morbidity, owing to a reduced incidence of postoperative pulmonary complications and because the need for single-lung ventilation in obviated ${ }^{33}$, and the present data may inform such discussions. However, minimally invasive approaches may produce similar benefits for patients with significant baseline pulmonary co-morbidity ${ }^{34}$, while producing favourable oncological outcomes even compared with open transthoracic resection $^{35,36}$.

Longer-term implications of reduced DLCO after nCRT were also observed, including reduced physical function scores and increased difficulty in taking a long outdoor walk among disease-free patients on HR-QoL analysis, consistent with long-term outcomes in the 
NeoRes trial ${ }^{25}$. Given the short- and long-term implications of reduced diffusion capacity, there is great impetus to develop an understanding of the factors, both patientand treatment-related, influencing individual risk. Clearly dose is important, with increased risk at greater total radiation doses, and increased irradiated lung volumes on DVH analysis $^{26,37,38}$. Although a DVH of V20 below 25 per cent was set in the present study, as in the CROSS protocol, clinical tumour stage tended to predict reduced percentage DLCO after treatment on multivariable analysis, probably reflecting planned clinical target volumes with greater lung exposure. Smoking also independently increased DLCO loss, an effect also reported in lung cancer, further emphasizing the need for smoking cessation in patients commencing multimodal protocols ${ }^{39}$.

The strength of the study is the detailed profiling of a large number of patients initially deemed fit for major surgery based on clinical assessment, with standard operative approaches underpinned by quality assurance measures. However, some limitations are acknowledged. First, although a DVH of V20 below 25 per cent was set for all patients, individual DVH re-analysis was beyond the scope of this study. Second, even though multivariable analysis was undertaken to minimize confounding between groups, the treatment allocation was not randomized, and so differences between the two chemoradiation protocols may be subject to uncontrolled bias. In addition, these data represent a single-centre experience; further multicentre collaborative efforts may lend external validity to the present data. Attrition during neoadjuvant therapy was significant compared with that in clinical trials ${ }^{3,40}$, but similar to that of previous consecutive cohort data ${ }^{41,42}$. Although three $\mathrm{RCTs}^{35,43-45}$ have reported reduced pulmonary morbidity with minimally invasive approaches, all patients in the present study underwent open surgery, so the implications for minimally invasive oesophagectomy are unclear. However, the present data provide a useful framework for further research in this context.

This study has demonstrated that nCRT, although rarely causing clinically evident radiation fibrosis, is associated with a significant decline in pulmonary diffusion capacity overall. Reduced pulmonary diffusion was associated with an increased risk of major postoperative complications and impaired long-term quality of life. Prospective detailed recording of operative morbidity and quality of life is embedded in ongoing RCTs including ESOPEC and NeoAEGIS (NEOadjuvant trial in Adenocarcinoma of the oEsophagus and oesophagoGastric junction International Study), which are comparing best current chemotherapy with the CROSS regimen, and these secondary endpoints will be of major interest, particularly if there is oncological equivalence ${ }^{46,47}$. At this time, notwithstanding advances in minimally invasive approaches, pulmonary complications remain the most common cause of postoperative major morbidity and mortality in oesophageal cancer surgery, and these data provide a rationale towards personalized treatment where pulmonary physiology, in particular diffusion capacity, a potentially targetable parameter, must be considered.

\section{Acknowledgements}

The authors acknowledge the support and contributions of J. Moore, Upper Gastrointestinal Cancer Coordinator; C. O'Farrell, Upper Gastrointestinal Clinical Trials Nurse, Department of Surgery, Trinity Centre and Institute of Molecular Medicine, St James's Hospital, Dublin, Ireland; and the Pulmonary Laboratory, St James's Hospital, Dublin, Ireland. Supported by a fellowship award from the Health Research Board, Ireland, to J.A.E. (HPF 2015-1013).

Disclosure: The authors declare no conflict of interest.

\section{References}

1 Low DE, Kuppusamy MK, Alderson D, Cecconello I, Chang AC, Darling G et al. Benchmarking complications associated with esophagectomy. Ann Surg 2019; 269: 291-298.

2 Lucas DJ, Pawlik TM. Quality improvement in gastrointestinal surgical oncology with American College of Surgeons National Surgical Quality Improvement Program. Surgery 2014; 155: 593-601.

3 van Hagen P, Hulshof MC, van Lanschot JJ, Steyerberg EW, van Berge Henegouwen MI, Wijnhoven BP et al.; CROSS Group. Preoperative chemoradiotherapy for esophageal or junctional cancer. N Engl 7 Med 2012; 366: 2074-2084.

4 Kumagai K, Rouvelas I, Tsai JA, Mariosa D, Klevebro F, Lindblad $\mathrm{M}$ et al. Meta-analysis of postoperative morbidity and perioperative mortality in patients receiving neoadjuvant chemotherapy or chemoradiotherapy for resectable oesophageal and gastro-oesophageal junctional cancers. $\mathrm{Br}$ 7 Surg 2014; 101: 321-338.

5 Mariette C, Dahan L, Mornex F, Maillard E, Thomas PA, Meunier B et al. Surgery alone versus chemoradiotherapy followed by surgery for stage I and II esophageal cancer: final analysis of randomized controlled phase III trial FFCD 9901. 7 Clin Oncol 2014; 32: 2416-2422.

6 Stahl M, Walz MK, Riera-Knorrenschild J, Stuschke M, Sandermann A, Bitzer M et al. Preoperative chemotherapy versus chemoradiotherapy in locally advanced adenocarcinomas of the oesophagogastric junction (POET): long-term results of a controlled randomised trial. Eur 7 Cancer 2017; 81: 183-190.

7 Klevebro F, Alexandersson von Döbeln G, Wang N, Johnsen G, Jacobsen AB, Friesland $\mathrm{S}$ et al. A randomized clinical trial of neoadjuvant chemotherapy versus neoadjuvant 
chemoradiotherapy for cancer of the oesophagus or gastro-oesophageal junction. Ann Oncol 2016; 27: 660-667.

8 Blencowe NS, Strong S, McNair AG, Brookes ST, Crosby T, Griffin SM et al. Reporting of short-term clinical outcomes after esophagectomy: a systematic review. Ann Surg 2012; 255: 658-666.

9 Aaronson NK, Ahmedzai S, Bergman B, Bullinger M, Cull A, Duez NJ et al. The European Organization for Research and Treatment of cancer QLQ-C30: a quality-of-life instrument for use in international clinical trials in oncology. 7 Natl Cancer Inst 1993; 85: 365-376.

10 Lagergren P, Fayers P, Conroy T, Stein HJ, Sezer O, Hardwick R et al.; European Organisation for Research Treatment of Cancer Gastrointestinal and Quality of Life Groups. Clinical and psychometric validation of a questionnaire module, the EORTC QLQ-OG25, to assess health-related quality of life in patients with cancer of the oesophagus, the oesophago-gastric junction and the stomach. Eur 7 Cancer 2007; 43: 2066-2073.

11 Walsh TN, Noonan N, Hollywood D, Kelly A, Keeling N, Hennessy TP. A comparison of multimodal therapy and surgery for esophageal adenocarcinoma. N Engl F Med 1996; 335: 462-467.

12 Cunningham D, Allum WH, Stenning SP, Thompson JN, Van de Velde CJ, Nicolson M et al.; MAGIC Trial Participants. Perioperative chemotherapy versus surgery alone for resectable gastroesophageal cancer. $N$ Engl $7 \mathrm{Med}$ 2006; 355: 11-20.

13 Donohoe CL, O'Farrell NJ, Ravi N, Reynolds JV. Evidence-based selective application of transhiatal esophagectomy in a high-volume esophageal center. World 7 Surg 2012; 36: 98-103.

14 Reynolds JV, Donohoe CL, McGillycuddy E, Ravi N, O'Toole D, O'Byrne $\mathrm{K}$ et al. Evolving progress in oncologic and operative outcomes for esophageal and junctional cancer: lessons from the experience of a high-volume center. 7 Thorac Cardiovasc Surg 2012; 143: 1130-1137.e1.

15 Healy LA, Ryan A, Doyle SL, Ní Bhuachalla ÉB, Cushen S, Segurado R et al. Does prolonged enteral feeding with supplemental omega-3 fatty acids impact on recovery post-esophagectomy: results of a randomized double-blind trial. Ann Surg 2017; 266: 720-728.

16 Ryan AM, Reynolds JV, Healy L, Byrne M, Moore J, Brannelly $\mathrm{N}$ et al. Enteral nutrition enriched with eicosapentaenoic acid (EPA) preserves lean body mass following esophageal cancer surgery: results of a double-blinded randomized controlled trial. Ann Surg 2009; 249: 355-363.

17 Ryan AM, Rowley SP, Healy LA, Flood PM, Ravi N, Reynolds JV. Post-oesophagectomy early enteral nutrition via a needle catheter jejunostomy: 8-year experience at a specialist unit. Clin Nutr 2006; 25: 386-393.

18 Dindo D, Demartines N, Clavien PA. Classification of surgical complications: a new proposal with evaluation in a cohort of 6336 patients and results of a survey. Ann Surg 2004; 240: 205-213.
19 Slankamenac K, Graf R, Barkun J, Puhan MA, Clavien PA. The comprehensive complication index: a novel continuous scale to measure surgical morbidity. Ann Surg 2013; 258: $1-7$.

20 Low DE, Alderson D, Cecconello I, Chang AC, Darling GE, D'Journo XB et al. International consensus on standardizat ion of data collection for complications associated with esophagectomy: Esophagectomy Complications Consensus Group (ECCG). Ann Surg 2015; 262: 286-294.

21 Centers for Disease Control and Prevention. Pneumonia (Ventilator-associated [VAP] and non-ventilator-associated Pneumonia [PNEU]) Event; 2017. https://www.cdc.gov/nhsn/ PDFs/pscManual/6pscVAPcurrent.pdf [accessed 1 October 2018].

22 Graham BL, Brusasco V, Burgos F, Cooper BG, Jensen R, Kendrick A et al. 2017 ERS/ATS standards for single-breath carbon monoxide uptake in the lung. Eur Respir 7 2017; 49.

23 Stanojevic S, Graham BL, Cooper BG, Thompson BR, Carter KW, Francis RW et al.; Global Lung Function Initiative TLCO working group; Global Lung Function Initiative (GLI) TLCO. Official ERS technical standards: Global Lung Function Initiative reference values for the carbon monoxide transfer factor for Caucasians. Eur Respir 7 2017; 50: 1700010.

24 Quanjer PH, Stanojevic S, Cole TJ, Baur X, Hall GL, Culver BH et al.; ERS Global Lung Function Initiative. Multi-ethnic reference values for spirometry for the 3-95-yr age range: the global lung function 2012 equations. Eur Respir 7 2012; 40: 1324-1343.

25 von Döbeln GA, Nilsson M, Adell G, Johnsen G, Hatlevoll I, Tsai J et al. Pulmonary function and cardiac stress test after multimodality treatment of esophageal cancer. Pract Radiat Oncol 2016; 6: e53-e59.

26 Gergel TJ, Leichman L, Nava HR, Blumenson LE, Loewen GM, Gibbs JE et al. Effect of concurrent radiation therapy and chemotherapy on pulmonary function in patients with esophageal cancer: dose-volume histogram analysis. Cancer $\mathcal{F}$ 2002; 8: 451-460.

27 Abou-Jawde RM, Mekhail T, Adelstein DJ, Rybicki LA, Mazzone PJ, Caroll MA et al. Impact of induction concurrent chemoradiotherapy on pulmonary function and postoperative acute respiratory complications in esophageal cancer. Chest 2005; 128: 250-255.

28 Riedel M, Stein HJ, Mounyam L, Zimmermann F, Fink U, Siewert JR. Influence of simultaneous neoadjuvant radiotherapy and chemotherapy on bronchoscopic findings and lung function in patients with locally advanced proximal esophageal cancer. Am 7 Respir Crit Care Med 2000; 162: $1741-1746$.

29 Palma DA, Senan S, Tsujino K, Barriger RB, Rengan R, Moreno $\mathrm{M}$ et al. Predicting radiation pneumonitis after chemoradiation therapy for lung cancer: an international individual patient data meta-analysis. Int 7 Radiat Oncol Biol Phys 2013; 85: 444-450.

30 McCurdy M, McAleer MF, Wei W, Ezhil M, Johnson V, Khan $M$ et al. Induction and concurrent taxanes enhance 
both the pulmonary metabolic radiation response and the radiation pneumonitis response in patients with esophagus cancer. Int 7 Radiat Oncol Biol Phys 2010; 76: 816-823.

31 Ding NH, Li JJ, Sun LQ. Molecular mechanisms and treatment of radiation-induced lung fibrosis. Curr Drug Targets 2013; 14: 1347-1356.

32 Citrin DE, Prasanna PGS, Walker AJ, Freeman ML, Eke I, Barcellos-Hoff MH et al. Radiation-induced fibrosis: mechanisms and opportunities to mitigate. Report of an NCI workshop, September 19, 2016. Radiat Res 2017; 188: 1-20.

33 Hulscher JB, van Sandick JW, de Boer AG, Wijnhoven BP, Tijssen JG, Fockens $\mathrm{P}$ et al. Extended transthoracic resection compared with limited transhiatal resection for adenocarcinoma of the esophagus. N Engl 7 Med 2002; 347: 1662-1669.

34 Markar SR, Wiggins T, Antonowicz S, Zacharakis E, Hanna GB. Minimally invasive esophagectomy: lateral decubitus $v s$. prone positioning; systematic review and pooled analysis. Surg Oncol 2015; 24: 212-219.

35 Mariette C, Markar SR, Dabakuyo-Yonli TS, Meunier B, Pezet D, Collet D et al.; Fédération de Recherche en Chirurgie (FRENCH) and French Eso-Gastric Tumors (FREGAT) Working Group. Hybrid minimally invasive esophagectomy for esophageal cancer. N Engl 7 Med 2019; 380: $152-162$.

36 Biere SS, van Berge Henegouwen MI, Maas KW, Bonavina L, Rosman C, Garcia JR et al. Minimally invasive versus open oesophagectomy for patients with oesophageal cancer: a multicentre, open-label, randomised controlled trial. Lancet 2012; 379: 1887-1892.

37 Lee HK, Vaporciyan AA, Cox JD, Tucker SL, Putnam JB Jr, Ajani JA et al. Postoperative pulmonary complications after preoperative chemoradiation for esophageal carcinoma: correlation with pulmonary dose-volume histogram parameters. Int 7 Radiat Oncol Biol Phys 2003; 57: 1317-1322.

38 Wang SL, Liao Z, Vaporciyan AA, Tucker SL, Liu H, Wei X et al. Investigation of clinical and dosimetric factors associated with postoperative pulmonary complications in esophageal cancer patients treated with concurrent chemoradiotherapy followed by surgery. Int $\mathcal{F}$ Radiat Oncol Biol Phys 2006; 64: 692-699.

39 Weytjens R, Erven K. Radiation pneumonitis: occurrence, prediction, prevention and treatment. Belg 7 Med Oncol 2013; 7: $105-110$.
40 Shapiro J, van Lanschot JJB, Hulshof MCCM, van Hagen P, van Berge Henegouwen MI, Wijnhoven BPL et al.; CROSS study group. Neoadjuvant chemoradiotherapy plus surgery versus surgery alone for oesophageal or junctional cancer (CROSS): long-term results of a randomised controlled trial. Lancet Oncol 2015; 16: 1090-1098.

41 Gilbert S, Gresham GK, Jonker DJ, Seely AJ, Maziak DE, Shamji FM et al. Impact of patient selection, disease progression, and adverse events on esophageal cancer outcomes after trimodality therapy. Ann Thorac Surg 2012; 94: 1659-1666.

42 Findlay JM, Gillies RS, Franklin JM, Teoh EJ, Jones GE, di Carlo $\mathrm{S}$ et al. Restaging oesophageal cancer after neoadjuvant therapy with ${ }^{18} \mathrm{~F}$-FDG PET-CT: identifying interval metastases and predicting incurable disease at surgery. Eur Radiol 2016; 26: 3519-3533.

43 Straatman J, van der Wielen N, Cuesta MA, Daams F, Roig Garcia J, Bonavina L et al. Minimally invasive versus open esophageal resection: three-year follow-up of the previously reported randomized controlled trial: the TIME trial. Ann Surg 2017; 266: 232-236.

44 Briez N, Piessen G, Bonnetain F, Brigand C, Carrere N, Collet D et al. Open versus laparoscopically-assisted oesophagectomy for cancer: a multicentre randomised controlled phase III trial - the MIRO trial. BMC Cancer 2011; 11: 310.

45 van der Sluis PC, van der Horst S, May AM, Schippers C, Brosens LAA, Joore HCA et al. Robot-assisted minimally invasive thoracolaparoscopic esophagectomy versus open transthoracic esophagectomy for resectable esophageal cancer: a randomized controlled trial. Ann Surg 2019; 269: 621-630.

46 Hoeppner J, Lordick F, Brunner T, Glatz T, Bronsert P, Röthling N et al. ESOPEC: prospective randomized controlled multicenter phase III trial comparing perioperative chemotherapy (FLOT protocol) to neoadjuvant chemoradiation (CROSS protocol) in patients with adenocarcinoma of the esophagus (NCT02509286). BMC Cancer 2016; 16: 503.

47 Reynolds JV, Preston SR, O’Neill B, Baeksgaard L, Griffin SM, Mariette C et al. ICORG 10-14: NEOadjuvant trial in Adenocarcinoma of the oEsophagus and oesophagoGastric junction International Study (Neo-AEGIS). BMC Cancer 2017; 17: 401.

\section{Supporting information}

Additional supporting information can be found online in the Supporting Information section at the end of the article. 